\title{
Proliferative vitreoretinopathy: current and emerging treatments
}

This article was published in the following Dove Press journal:

Clinical Ophthalmology

13 August 2012

Number of times this article has been viewed

\author{
Ama Sadaka' \\ Gian Paolo Giuliari ${ }^{2,3}$ \\ 'Department of Ophthalmology, \\ Massachusetts Eye and Ear Infirmary, \\ Boston, MA, USA; ${ }^{2}$ Centro de \\ Cirugía Oftalmológica (CECOF), \\ Caracas, Venezuela; ${ }^{3}$ Department of \\ Ophthalmology, Domingo Luciani \\ Hospital, Caracas, Venezuela
}

\begin{abstract}
Proliferative vitreoretinopathy is a disease process that follows the proliferation of ectopic cell sheets in the vitreous and/or periretinal area, causing periretinal membrane formation and traction, in patients with rhegmatogenous retinal detachments. Currently, vitreous surgery is the standard treatment; however, the results aren't satisfactory given the vision loss that ensues and that redetachment is relatively common. It is becoming clearer that there exists an interplay between various cytokines/growth factors, matrix proteins, and the different cell types that drive the undesirable formation of periretinal membranes. This fundamental understanding is aiding in identifying different adjunct agents that can block the cellular events intrinsic to proliferative vitreoretinopathy. In this review, we describe the current understanding on the pathogenesis and discuss how the fundamental understanding of the biochemical/molecular events is instrumental in developing the novel treatment strategies that are also highlighted.
\end{abstract}

Keywords: proliferative vitreoretinopathy, retinal detachment, vision loss

\section{Introduction}

The term proliferative vitreoretinopathy (PVR) was coined in 1983 by the Retina Society Terminology committee ${ }^{1}$ to describe a disease process that follows rhegmatogenous retinal detachment (RRD) secondary to the occurrence and proliferation of ectopic cell sheets in the vitreous and/or periretinal area, causing membrane formation and traction. This disease process occurs in 5\%-10\% of all RRD and is implicated in redetachment after surgery in $75 \%$ of cases, ${ }^{2}$ remaining a major barrier to successful repair of RD. Currently, vitreous surgery is the standard treatment; however, recurrent vitreoretinal traction can lead to redetachment, extensive reproliferation of membranes, and significant visual loss. In this review, we describe the current understanding on the pathogenesis of PVR and discuss how the fundamental understanding of the biochemical/molecular events is instrumental in developing the novel treatment strategies that are also highlighted.

\section{Pathogenesis and risk factors}

PVR is characterized by migration and proliferation of cells following a break in the retina or trauma (Figure 1), leading to formation of membranes in the periretinal area, followed by contraction of the cellular membranes and traction on the retina that causes RD (Figure 2). It is analogous to a dynamic wound-healing process following tissue injury (the retinal break and/or ocular trauma being the insult in this case) that includes inflammation, proliferation, and modulation of scar that can either go through normal
Correspondence: Gian Paolo Giuliar Centro de Cirugía Oftalmológica (CECOF), Av Francisco de Miranda, Torre Cavendes, Piso 6, Ofic 6-04, Altamira, Caracas, Venezuela

Tel +58 2I 22852433

Fax +582122850047

Email gpgiuliari@gmail.com 


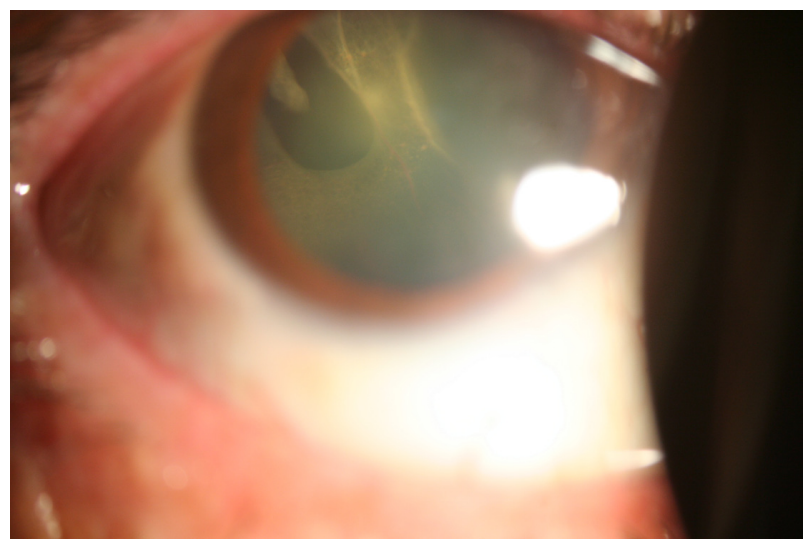

Figure I Slit-lamp biomicroscopy photograph showing a retinal detachment behind the crystalline lens associated with a superotemporal horseshoe tear.

ocular wound healing with tissue remodeling and repair or can take an abnormal path with protracted wound healing, for which the mechanism is not yet fully understood. ${ }^{3}$

RRD causes a breakdown in the blood-retinal barrier (BRB), triggering cell migration and proliferation, with the principal cells involved being the retinal pigment epithelial (RPE) cells, fibrous astrocytes, fibroblasts, myofibroblasts, and macrophages. ${ }^{4}$ This also causes chemotaxis of inflammatory cells like macrophages, lymphocytes, and polymorphonuclear cells involved in the healing process. ${ }^{5}$ Following detachment, the monolayer RPE cells that had become postmitotic early in development, and that had assumed specialized roles to support photoreceptors in visual transduction, migrate and form dedifferentiated cells within a provisional extracellular matrix containing collagen, fibronectin, thrombospondin, and other matrix proteins. ${ }^{5}$ Different signals have been found to play a role

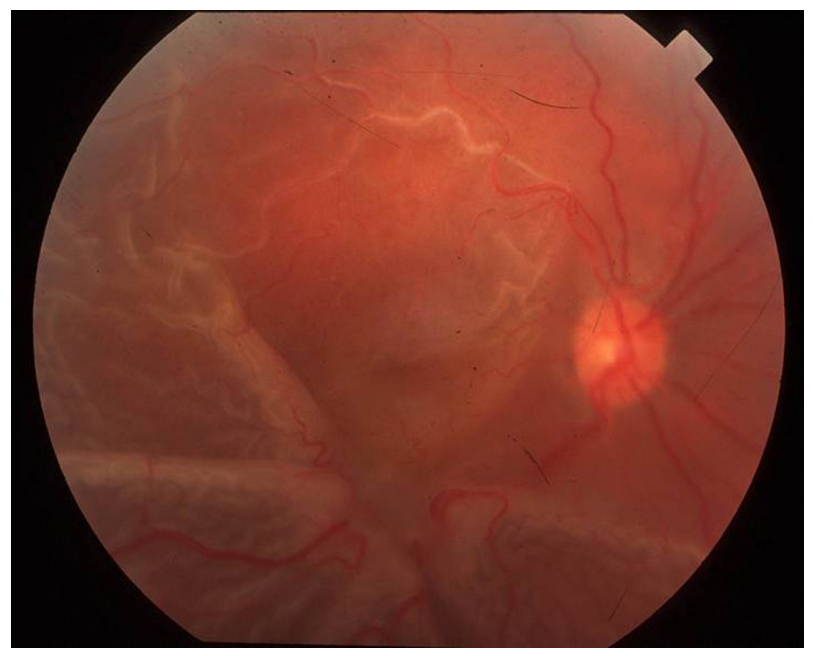

Figure 2 Fundus photograph showing a star fold from a proliferative vitreoretinopathy in a patient with a history of a retinal detachment. in migration and proliferation of RPE cells, including loss of contact, signaling from photoreceptors, and response to factors present in the vitreous, in addition to other signals secreted by inflammatory cells.

First, loss of contact for RPE cells and loss of signaling from adjacent cells induces their proliferation and dedifferentiation to repair the defect. ${ }^{6,7}$ Glial cells proliferate too and migrate on both sides of the detached retina, contributing to poor recovery of vision. This is evidenced by in vitro and in vivo studies, whereby RPE cells and retinal glial cells assume different phenotypes when placed in a diffusion chamber and when implanted into the vitreous cavity of rabbits. ${ }^{8}$ Moreover, there appears to be a correlation between the amount of BRB breakdown, chemotaxis, and mitogenic activity, and the speed and severity of the retinal detachment that follows. ${ }^{9}$ The separation of the outer retina from the choroid induces ischemia of the outer retina, causing death of photoreceptors by necrosis and apoptosis, which also contributes to the vision loss. ${ }^{10,11}$

This migration, proliferation, and differentiation inside the vitreous is influenced to a great extent by the growth factors and cytokines present in the vitreous that retinal cells become exposed to following the retinal break or to factors that get access to the eye from the circulation. Evidence comes from their identification in pathological vitreous and in epiretinal membranes, and from in vitro and in vivo experiments that unveil their contributory role. Growth factors identified that are likely involved in regulation of cell growth include platelet-derived growth factor (PDGF), tumor growth factor-beta (TGF- $\beta$ ), epidermal growth factor (EGF), tumor necrosis factor-alpha (TNF- $\alpha$ ), TNF- $\beta$, fibroblast growth factor (FGF), and others. Cytokines like interleukin-1 (IL-1), IL-6, IL-8, IL-10, and interferon-gamma (INF- $\gamma$ ) have also been identified. Those growth stimuli, a few of which are discussed below, are believed to contribute to cell-growth regulation in PVR. ${ }^{12}$

PDGF and its receptor (PDGFR) are main players, and are gaining more attention as novel therapeutic targets. PDGF is a growth factor that exists as a dimer and acts as a chemoattractant, a mitogen, and a mediator of cellular contraction for RPE cells. Several gene products constitute PDGF, being PDGF-A, PDGF-B, PDGF-C, and PDGF-D. The receptors for PDGF are encoded for by two genes that can homodimerize or heterodimerize forming PDGFR- $\alpha \alpha$, PDGF- $\beta \beta$ and PDGFR- $\alpha \beta .^{13}$ Both $\alpha$ and $\beta$ forms have been identified in epiretinal membrane samples; however, PDGFR- $\alpha$ is more readily activated and is more efficient at inducing PVR. ${ }^{14}$ Furthermore, vitreal PDGF isoforms preferentially 
activate the $\alpha$-form receptor. ${ }^{15}$ High levels of PDGF become detectable in the vitreous of animals that develop PVR, with PDGF-C being the predominant isoform. ${ }^{15}$ Increased expression of PDGF-A in the retina showed formation of epiretinal membranes and RD with proliferation of RPE cells and glial cells. ${ }^{16,17}$ Moreover, RPE cells injected into vitreous can develop PVR depending on their ability to respond to PDGFR $^{18}$ especially that RPE cells upregulate the expression of the PDGF ligands and receptors in response to different signals like loss of contact with neighboring cells. ${ }^{19}$ The use of genetically modified fibroblasts, for instance, revealed that the expression of functional PDGFR was essential for experimental PVR. ${ }^{20}$ Cells with no PDGFR carried a low potential to develop PVR and were able to revert back to PVR reexpression upon reestablishment of the wild-type PDGFR. Similarly, blocking PDGFR reduced the potential of PVR development. ${ }^{18,21}$ Further investigations to understand better the mechanism of action of PDGF and PDGFR and their contribution to PVR led to some surprising and important discoveries. It was found that blocking PDGF is not sufficient to block PVR and that experimental PVR was dependent on the PDGFR- $\alpha$ activation, which turned out to be activated by PDGF as well as non-PDGF agents like FGF, insulin, EGF, and hepatocyte growth factor. ${ }^{18,20-22}$ This indirect route activates the PDGFR through a different mechanism than the direct pathway that requires the receptor's ligand-binding domain. The non-PDGF agents cause an increase in intracellular reactive oxygen species that cause activation of the Src family kinase, leading to phosphorylation of the receptor and thus promotion of PVR. ${ }^{23}$ More recently, it was also found that vascular endothelial growth factor A (VEGF-A) involved in neovascularization competitively blocks PDGF-dependent binding and activation of PDGFR- $\alpha{ }^{24}$

Clinical studies looking at the role of PDGF are in agreement with animal experiments. Cassidy et al looked at 38 vitreous samples for patients undergoing vitrectomy for a variety of vitreoretinal disorders and found that patients with PVR had elevated concentrations of FGF and PDGF when compared to patients with RD uncomplicated by PVR. ${ }^{25}$ Analysis of epiretinal membranes from PVR patients revealed the presence of both PDGF and PDGFR expressed by RPE cells and glial cells. ${ }^{14}$ In agreement with animal studies, Lei et al found that the presence of PDGF in the vitreous cavity is tightly associated with PVR, as eight of nine PVR patients had detectable levels of PDGF, mainly PDGF-C, whereas only one of 16 patients with other different types of retinal diseases requiring surgery/vitrectomy had PDGF detectable in the vitreous. ${ }^{15}$
TGF- $\beta$ is another growth factor thought to be implicated in PVR pathogenesis. It is a potent chemoattractant that was found to be secreted by RPE cells, fibroblasts, platelets and macrophages ${ }^{5,26}$ with TGF- $\beta_{2}$ being the predominant form in the posterior segment of primate eyes. ${ }^{27}$ It plays a key role in transforming RPE cells into mesenchymal fibroblastic cells and in inducing type I collagen synthesis in RPE cells through different pathways, causing fibrosis. ${ }^{28,29} \mathrm{TGF}-\beta_{2}$, like PDGF, was found to increase RPE-mediated contraction of bovine retinal explants. This effect on retinal contraction was inhibited by neutralizing antibodies to both growth factors. ${ }^{30}$ The use of IL-10 also, an antagonist of TGF- $\beta$, decreased the contraction by $63 \% .{ }^{30}$ Similar to PDGF, TGF- $\beta$ levels were found to be higher in human vitreous of patients with PVR. ${ }^{31,32}$ The in vivo evidence on the role of this cytokine in PVR pathogenesis comes from experiments like that by Nassar et al, who used decorin, a naturally occurring TGF- $\beta$ inhibitor, in a rabbit model of PVR. They found that adjuvant decorin application during vitrectomy reduced fibrosis and RD development. ${ }^{33}$ Moreover, fasudil, a potent inhibitor of a key downstream mediator of TGF- $\beta$ called Rho-kinase, was found to significantly inhibit PVR progression in the experimental model without apparent retinal cell toxicity, elucidating the role of TGF- $\beta$ in this disease. ${ }^{34}$

\section{Classification and risk factors}

The classification of PVR and the identification of risk factors are crucial for better reporting and better treatment of the disease. The Retina Society first devised a classification for PVR that subdivided it into stages A, B, C, and D that increased in severity from minimal PVR to massive PVR. The classification was most recently modified in 1991 to distinguish between anterior and posterior location of the proliferation and to offer a more detailed description of the contraction types (ie, focal, diffuse, subretinal, circumferential, and anterior displacement). It divided PVR into three grades: A, B, and C. Grade A is limited to the presence of vitreous cells or haze. Grade B describes subclinical contraction, defined by rolled or irregular edges of a tear or inner retinal surface wrinkling. Grade $\mathrm{C}$ is denoted by the presence of preretinal or subretinal membranes, and is further subdivided based on the number of hours involved and the location: $\mathrm{Ca}$ being anterior to the equator and $\mathrm{Cb}$ being posterior to the equator. ${ }^{35}$

All RRD go through the healing process, but only a few develop PVR, making the presence of risk factors central for the production and persistence of the hyperplastic fibrotic tissue and making identification of risk factors crucial for 
establishing pharmacologic prophylaxis that cannot be given to all RD patients. Considering the pathobiology of PVR, it would make sense to consider that any factor that increases intraocular inflammation or causes release of RPE cells into the vitreous can stimulate development of this condition. Several studies have focused on the identification of a large number of risk factors and associations for the development of PVR, some of which are more consistent than others. These encompass multiple tears and giant tears, large RD ( $>2$ quadrants), vitreous hemorrhage, preoperative PVR, preoperative and postoperative choroidal detachment, signs of uveitis, aphakia, use of vitrectomy in repair of RD, treatment with cryopexy, endolaser application, repeated surgical procedures, and use of air or sulfur hexafluoride $\left(\mathrm{SF}_{6}\right)^{2,36-38}$ Researchers are also investigating the potential of a combined assessment of clinical risk factors with biomarker profiling for markers like IL-3, chemokine ligand-22 and macrophage migration inhibitory factor for better prediction of PVR risk following RD surgery. ${ }^{39}$

\section{Current and emerging treatments for proliferative vitreoretinopathy Surgery}

Surgery has been the standard treatment for PVR. There have been tremendous advances in surgical techniques and technology in the ophthalmology field, including those for management of PVR; however, recurrent detachment is common. The aims of surgery are to relieve the tractional forces, as well as to close the retinal break while restoring the normal anatomy and the ciliary body function as much as possible. Light and moderate cases are usually treated by conventional surgery, but more advanced cases require technically difficult surgeries that involve scleral buckling, vitrectomy, membrane peeling, use of perfluorocarbon liquids, retinotomies, and internal tamponade with silicone oil/gas. ${ }^{2}$ Anatomic success following surgery is reported to be $60 \%-80 \%,{ }^{37}$ depending on the severity of the cases; however, functional success (ambulatory vision 5/200 or better) is seen in only $40 \%-80 \%$ of patients who are considered to have anatomically successful surgeries. Given the complexity of PVR, the uncertainty of improvement, and the ongoing better understanding of the disease, different pharmacologic adjuncts targeting the different phases of the process are needed and are being explored.

\section{Pharmacologic agents}

Different drugs and drug-delivery systems have been tested for the treatment of PVR. Short drug half-lives are always a concern in such a condition following intravitreal and/or subconjunctival injections. This has led to the development of such sustained-release systems as liposome-encapsulated medications, ${ }^{40}$ solid implant polymers, ${ }^{41}$ biodegradable microspheres, ${ }^{42}$ and others. Drugs under investigation target one or more (combination therapy) of the involved pathologies, including anti-inflammatory agents, antiproliferative agents, antineoplastic agents, antigrowth-factor agents, and antioxidant agents.

\section{Anti-inflammatories}

The use of corticosteroids was one of the first agents tested. Animal experimental studies showed benefit with intravitreal administration of triamcinolone. Hui et al induced PVR in a rabbit model by injecting activated macrophages into the vitreal cavity, followed by early treatment with $1 \mathrm{mg}$ intravitreal triamcinolone. They found a $64.2 \%$ reduction in the $\mathrm{RD}$ rate. ${ }^{43}$ Tano et al injected rabbit-skin fibroblasts into the vitreous and then provided $1 \mathrm{mg}$ of triamcinolone intravitreally. They found a $50 \%$ reduction in the incidence of $\mathrm{RD}$ and $64 \%$ reduction in neovascularization. ${ }^{44}$ Giving methylprednisone periocularly to rabbits also showed a decrease in the incidence of PVR created by retinal tears/detachment, cryotherapy, and injection of PDGF, from $87 \%$ to $13 \%{ }^{45}$

Despite the success seen with steroids in animal experiments, human studies failed to demonstrate the same beneficial effect. In one study, Koerner et al showed minimal difference in postoperative retinal fibrosis following systemic steroid administration 5 days after surgery. ${ }^{46}$ On the contrary, Hui and Hu suggested that earlier administration of steroids may be more effective in showing a difference. ${ }^{47}$ Later, Jonas et al reported the results of a pilot study in which they enrolled 16 patients who underwent pars plana vitrectomy for PVR treatment and received an intravitreal injection of 10-20 mg crystalline triamcinolone acetonide at the end of surgery. The control group consisted of 144 patients who only underwent PPV. They reported a decrease in postoperative inflammation; however, the mean postoperative follow-up period was less than 2 months. ${ }^{48} \mathrm{~A}$ more recent prospective placebo-controlled double-blind clinical trial on 34 patients with RRD scheduled for scleral buckling RD surgery gave patients $0.5 \mathrm{~mL}$ subconjunctival injection of dexamethasone diphosphate or placebo 5-6 hours preoperatively. They found a statistically significant decrease in laser flare measurements at 1 week postoperatively, suggesting that steroid priming might be useful in reducing BRB breakdown and hence PVR; however, the follow-up period in this study was short too. ${ }^{49}$ Another retrospective interventional case series on 
37 patients with PVR grade C or D assessed the role of low-dose intravitreal triamcinolone as adjunctive treatment to vitrectomy and silicone oil tamponade. They found that $2 \mathrm{mg}$ intravitreal triamcinolone appears to be safe and effective. ${ }^{50}$

\section{Antineoplastic/antiproliferative agents}

Following the break in the BRB and inflammation, the proliferative phase ensues, thus antineoplastic agents inhibiting cell cycle and cellular proliferation are being extensively explored and their intraocular toxicity levels are being established. These include compounds like 5-fluorouracil (5-FU), daunorubicin, taxol, colchicine, retinoic acid, ribozymes, vincristine, cisplatin, adriamycin, mitomycin, dactomycin and others.

$5-\mathrm{FU}$ is one of the most tested compounds for the treatment of PVR, particularly in that it is frequently used to reduce scarring in glaucoma-filtering surgeries. It acts on DNA synthesis by inhibiting thymidine formation. Borhani et al evaluated a sustained-release bioerodible device in a rabbit model of PVR, where devices containing $0.5 \mathrm{mg}$ and $1 \mathrm{mg}$ 5-FU showed significant efficacy in preventing PVR, with the higher-concentration implant being 100\% effective in preventing tractional RD. ${ }^{41}$ In humans, two recent randomized controlled trials compared 5-FU and placebo with low-molecular-weight heparin (LMWH), which reduces postoperative fibrin after vitrectomy by binding to fibronectin and growth factors. ${ }^{51,52}$ The first trial involved 174 patients undergoing primary vitrectomy for RRD that were randomized to receive either $200 \mu \mathrm{g} / \mathrm{mL} 5$-FU and $5 \mathrm{IU} / \mathrm{mL} \mathrm{LMWH}$, or placebo in the infusion solution. They found a significant reduction in the incidence of postoperative PVR and in the reoperation rates in the treatment group. ${ }^{51}$ In the other study, Wickham et al studied 641 patients presenting with primary RRD who were undergoing vitrectomy and gas tamponade. ${ }^{52}$ They found that adjuvant therapy with 5-FU and LMWH did not improve the anatomic and visual success rates after 6 months. The differences between those studies could be explained by the dissimilarity in the inclusion criteria employed in each study, whereby the former study included high-risk patients, while the latter included all patients with RRD. ${ }^{53}$

Daunorubicin is a topoisomerase inhibitor that inhibits DNA and RNA synthesis in a cell cycle-independent manner and has also been tested for PVR. The Daunomycin Study Group was a multicenter, prospective, randomized, controlled clinical trial that assessed the efficacy and safety of daunorubicin during vitrectomy in eyes with PVR. ${ }^{54}$
They enrolled 286 patients with stage $\mathrm{C} 2$ or more advanced PVR and assigned them to either surgery with silicone oil alone or surgery with 10 -minute daunorubicin $(75 \mu \mathrm{g} / \mathrm{mL})$ perfusion. They found a similar anatomic success rate with a tendency towards higher rates of reattachment and a significant number of reoperations, but no difference in bestcorrected visual acuity. Kumar et al randomized 30 patients with a primary RD and PVR of stage D1 or worse, to either receive $5 \mu \mathrm{g}$ daunorubicin at the end of the vitrectomy or to a control group that just got the vitrectomy. Patients in the daunorubicin group achieved higher retinal attachment $(86.6 \%$ vs $66.6 \%)$, better best-corrected visual acuity $\geq 3 / 60$ $(60 \%$ vs $33.3 \%)$ and less postoperative vitreous reaction. ${ }^{55}$

Following membrane formation, cell contractility is what causes the traction and thus the RRD, therefore agents like taxol and colchicine that stabilize/inhibit microtubule formation can inhibit RPE and fibroblast migration and proliferation. ${ }^{56}$ Taxol $(0.5 \mu \mathrm{g})$ injected intravitreally into a PVR animal model reduced the incidence and extent of PVR. ${ }^{57}$ Another group looked at giving taxol immediately after injecting corneal fibroblasts and 3 days later. They found that earlier administration showed reduced incidence of RD that was not seen in the group that received it later, although that group had a reduced severity of PVR. ${ }^{58}$ On the other hand, low-dose oral colchicine (1.2 mg/day) given to patients with PVR associated with different conditions failed to show a significant difference between the treated group and the control. ${ }^{59}$

Retinoic acid (RA) is another attractive agent, given its properties in promoting growth arrest of RPE cells in vitro. ${ }^{60}$ Its benefit has been shown in a few studies. In a small sample retrospective study of 20 patients with RD secondary to a PVR, ten patients were given $40 \mathrm{mg}$ oral 13-cis-RA twice daily for 4 weeks postoperatively, and ten patients served as control. They found an increase in the rate of retinal attachment in the treated group (9/10) as compared to the control group (4/10). ${ }^{61}$ In a more recent study, Chang et al published the results of a prospective controlled interventional case series of 35 eyes with RRD and PVR who were randomized to receive either $10 \mathrm{mg}$ oral RA twice daily for 8 weeks postoperatively (16 patients) or no treatment (19 patients). Patients in the treated group had significantly lower rates of macular pucker formation with higher rates of ambulatory vision. ${ }^{62}$

Glucosamine, an inhibitor of $N$-linked oligosaccharide biosynthesis and processing, ${ }^{63}$ has been reported to inhibit growth of various cell types, ${ }^{64}$ thus has antiproliferative effects in addition to its anti-inflammatory effects in ocular inflammatory disorders. ${ }^{65,66}$ In PVR, glucosamine was found 
to effectively suppress RPE cell proliferation in vitro through modification of $N$-glycans on EGF receptors. ${ }^{67}$ Glucosamine could also inhibit the TGF- $\beta$ signaling pathway in RPE cells and the associated downstream events that lead to their differentiation and proliferation in PVR ${ }^{68}$ It also abrogated the morphologic effects of TGF- $\beta_{2}$ on RPE cells in vitro and in a mouse in vivo model. ${ }^{68}$

DNA-RNA chimeric ribozymes targeting proliferating cell nuclear antigen ( $P C N A)$, a cell cycle-controlling gene that inhibits cell division, have been tested. Ribozymes are small RNA molecules with endoribonuclease activity that hybridize to complementary sequences of a particular target mRNA transcript and cleave a sequence-specific target. This $P C N A$ ribozyme tested in a PVR rabbit model was efficacious in the treatment/prevention of PVR. ${ }^{69}$ In humans, ribozyme VIT100 was tested in a multicenter, double-masked, placebocontrolled, randomized clinical trial that enrolled 154 patients with established PVR (grade C or worse) undergoing vitrectomy for retinal reattachment repair. However, VIT100 was not effective in preventing PVR recurrence in this patient population. $^{70}$

Other agents tested include etoposide and tacrolimus. Etoposide, a topoisomerase II inhibitor, given intravitreally to rabbits with PVR, showed a significantly lower PVR severity without changes in the electroretinogram B-wave amplitude when $0.02 \mathrm{mg}$ were given at a dose of $10 \mu \mathrm{g} / \mathrm{mL} .^{71}$ Tacrolimus is an immunosuppressive agent that is mainly used in patients undergoing organ transplant. Intravitreal injection of tacrolimus into the eyes of guinea pigs in a PVR model showed a significantly decreased severity of PVR with significantly decreased levels of TGF- $\beta$, PDGF, and FGF when compared to control, with an improvement in epiretinal membrane formation. ${ }^{72}$

\section{Antigrowth factor/growth factor pathway inhibitors}

With the increasing knowledge about the role that growth factors play in the pathogenesis of PVR, there has been a move towards blocking growth factors and their respective pathways as a means to halt progression of PVR.

Kinase inhibitors are being explored. Hypericin, for example, which is used as an antidepressant and antiretroviral, acts as an antiproliferative through inhibition of the protein kinase $\mathrm{C}$ pathway. Intravitreal injections of hypericin in a PVR rabbit model ameliorated the PVR outcome following a single injection of the drug. ${ }^{73}$ Another more recent study using a PVR ocular trauma model also showed a benefit for hypericin in decreasing PVR progression. ${ }^{74}$ Tyrosine kinase inhibitors like herbimycin A have also been tested in a rabbit PVR model. They showed reduction in the number and severity of tractional retinal detachments when injected early; however, there was an initial drop in the electroretinogram B-wave amplitude following the injection, but that recovered subsequently. ${ }^{75}$ Alkylphosphocholine is yet another inhibitor of protein kinase $\mathrm{C}$ with antineoplastic and antiparasitic activity. It was found to be effective against RPE cell attachment, spreading, migration, and proliferation in vitro and was also identified as a promising agent in reducing the number of dividing Müller cells following RD in vivo. ${ }^{76}$ PDGFR kinase inhibitor AG1295 (100 mM) given intravitreally following injection of conjunctival fibroblasts to rabbit eyes showed a significantly attenuated development of RD without apparent histologic or retinal functional damage. ${ }^{21}$

TGF- $\beta$ is another key player in the pathogenesis of this disease, given its role in extracellular matrix production, membrane contraction, and inflammation, and given data from human studies. Testing tranlisat, an inhibitor of TGF- $\beta_{1}$ used as an antiallergy drug, showed promising results in terms of reducing the severity of PVR following intravitreal injection in a rabbit model without apparent toxicity to the eye, thus future investigations might prove agents like tranlisat to be effective in treating PVR in affected patients. ${ }^{77}$ Gene transfer of soluble TGF- $\beta$ type II receptor using an adenoviral vector into rabbit eyes that had received intravitreal conjunctival fibroblasts showed a significant reduction in the average severity of PVR in the treated group as compared to the control group. ${ }^{78}$

A few other studies using intravenous suramin, an antiparasitic that affects growth factor binding, ${ }^{79}$ matrix metalloprotease inhibitors like prinomastat that degrade extracellular matrix components and are important in the remodeling phase of tissue repair, and mitomycin $\mathrm{C}^{80}$ also showed promising inhibitory effects on PVR development.

$N$-acetylcysteine (NAC), an antioxidant used in a variety of clinical settings, has also gained interest. The rationale behind its use stems from the indirect PDGFR activation through an intracellular increase in reactive oxygen species. Injecting NAC into rabbit eyes was capable of protecting rabbits from PVR by blocking the vitreous-driven activation of PDGFR- $\alpha$. NAC also protected rabbits from developing $\mathrm{RD}$, although it didn't prevent formation of an epiretinal membrane. ${ }^{81}$

\section{Conclusion}

There is an emerging complex picture around the biochemical/ molecular events that drive the pathogenesis of PVR. It is 
becoming clearer that there exists an interplay between various cytokines/growth factors, matrix proteins, and the different cell types that drive the undesirable formation of periretinal membranes. This fundamental understanding added to the unsatisfactory success rate of surgery is aiding in identifying the choice and efficacy of different adjunct agents that can block the cellular events intrinsic to PVR. Based on what was discussed earlier, it looks like there is a cascade of events involved that might require combination therapy to target different stages simultaneously. Some of the approaches employed have shown some success in animal models and limited human trials; however, none has been widely successful, and more needs to be done to achieve better visual outcome prophylactically and therapeutically in PVR.

\section{Disclosure}

No funding support to disclose/no proprietary or financial interest to disclose.

\section{References}

1. [No authors listed]. The classification of retinal detachment with proliferative vitreoretinopathy. Ophthalmology. 1983;90(2):121-125.

2. Pastor JC. Proliferative vitreoretinopathy: an overview. Surv Ophthalmol. 1998;43(1):3-18.

3. Wilkins RB, Kulwin DR, Wendell L. Hughes Lecture. Wound healing. Ophthalmology. 1979;86(4):507-510.

4. Vinores SA, Campochiaro PA, Conway BP. Ultrastructural and electron-immunocytochemical characterization of cells in epiretinal membranes. Invest Ophthalmol Vis Sci. 1990;31(1):14-28.

5. Wiedemann P. Growth factors in retinal diseases: proliferative vitreoretinopathy, proliferative diabetic retinopathy, and retinal degeneration. Surv Ophthalmol. 1992;36(5):373-384.

6. Heriot WJ, Machemer R. Pigment epithelial repair. Graefes Arch Clin Exp Ophthalmol. 1992;230(1):91-100.

7. Anderson DH, Stern WH, Fisher SK, Erickson PA, Borgula GA. The onset of pigment epithelial proliferation after retinal detachment. Invest Ophthalmol Vis Sci. 1981;21(1 Pt 1):10-16.

8. Mueller-Jensen K, Machemer R, Azarnia R. Autotransplantation of retinal pigment epithelium in intravitreal diffusion chamber. $A m J$ Ophthalmol. 1975;80(3 Pt 2):530-537.

9. Campochiaro PA, Bryan JA 3rd, Conway BP, Jaccoma EH. Intravitreal chemotactic and mitogenic activity. Implication of blood-retinal barrier breakdown. Arch Ophthalmol. 1986;104(11):1685-1687.

10. Erickson PA, Fisher SK, Anderson DH, Stern WH, Borgula GA. Retinal detachment in the cat: the outer nuclear and outer plexiform layers. Invest Ophthalmol Vis Sci. 1983;24(7):927-942.

11. Cook B, Lewis GP, Fisher SK, Adler R. Apoptotic photoreceptor degeneration in experimental retinal detachment. Invest Ophthalmol Vis Sci. 1995;36(6):990-996.

12. Lei H, Rheaume MA, Kazlauskas A. Recent developments in our understanding of how platelet-derived growth factor (PDGF) and its receptors contribute to proliferative vitreoretinopathy. Exp Eye Res. 2010;90(3):376-381.

13. Heldin $\mathrm{CH}$, Westermark B. Platelet-derived growth factor: mechanism of action and possible in vivo function. Cell Regul. 1990;1(8): 555-566.

14. Cui J, Lei H, Samad A, et al. PDGF receptors are activated in human epiretinal membranes. Exp Eye Res. 2009;88(3):438-444.
15. Lei H, Hovland P, Velez G, et al. A potential role for PDGF-C in experimental and clinical proliferative vitreoretinopathy. Invest Ophthalmol Vis Sci. 2007;48(5):2335-2342.

16. Yamada H, Yamada E, Ando A, et al. Platelet-derived growth factor-Ainduced retinal gliosis protects against ischemic retinopathy. Am J Pathol. 2000;156(2):477-487.

17. Mori K, Gehlbach P, Ando A, et al. Retina-specific expression of PDGF-B versus PDGF-A: vascular versus nonvascular proliferative retinopathy. Invest Ophthalmol Vis Sci. 2002;43(6):2001-2006.

18. Ikuno Y, Leong FL, Kazlauskas A. Attenuation of experimental proliferative vitreoretinopathy by inhibiting the platelet-derived growth factor receptor. Invest Ophthalmol Vis Sci. 2000;41(10): 3107-3116.

19. Campochiaro PA, Hackett SF, Vinores SA, et al. Platelet-derived growth factor is an autocrine growth stimulator in retinal pigmented epithelial cells. J Cell Sci. 1994;107(Pt 9):2459-2469.

20. Ikuno Y, Kazlauskas A. An in vivo gene therapy approach for experimental proliferative vitreoretinopathy using the truncated platelet-derived growth factor alpha receptor. Invest Ophthalmol Vis Sci. 2002;43(7):2406-2411.

21. Zheng Y, Ikuno Y, Ohj M, et al. Platelet-derived growth factor receptor kinase inhibitor AG1295 and inhibition of experimental proliferative vitreoretinopathy. Jpn J Ophthalmol. 2003;47(2):158-165.

22. Lei H, Velez G, Hovland P, Hirose T, Gilbertson D, Kazlauskas A. Growth factors outside the PDGF family drive experimental PVR. Invest Ophthalmol Vis Sci. 2009;50(7):3394-3403.

23. Lei H, Kazlauskas A. Growth factors outside of the platelet-derived growth factor (PDGF) family employ reactive oxygen species/Src family kinases to activate PDGF receptor alpha and thereby promote proliferation and survival of cells. J Biol Chem. 2009;284(10): 6329-6336.

24. Pennock S, Kazlauskas A. Vascular endothelial growth factor A competitively inhibits platelet-derived growth factor (PDGF)-dependent activation of PDGF receptor and subsequent signaling events and cellular responses. Mol Cell Biol. 2012;32(10):1955-1966.

25. Cassidy L, Barry P, Shaw C, Duffy J, Kennedy S. Platelet derived growth factor and fibroblast growth factor basic levels in the vitreous of patients with vitreoretinal disorders. Br J Ophthalmol. 1998;82(2): 181-185.

26. Tanihara H, Yoshida M, Matsumoto M, Yoshimura N. Identification of transforming growth factor-beta expressed in cultured human retinal pigment epithelial cells. Invest Ophthalmol Vis Sci. 1993;34(2): 413-419.

27. Pfeffer BA, Flanders KC, Guerin CJ, Danielpour D, Anderson DH. Transforming growth factor beta 2 is the predominant isoform in the neural retina, retinal pigment epithelium-choroid and vitreous of the monkey eye. Exp Eye Res. 1994;59(3):323-333.

28. Yokoyama K, Kimoto K, Itoh Y, et al. The PI3K/Akt pathway mediates the expression of type I collagen induced by TGF-beta2 in human retinal pigment epithelial cells. Graefes Arch Clin Exp Ophthalmol. 2012; 250(1):15-23.

29. Kimoto K, Nakatsuka K, Matsuo N, Yoshioka H. p38 MAPK mediates the expression of type I collagen induced by TGF-beta 2 in human retinal pigment epithelial cells ARPE-19. Invest Ophthalmol Vis Sci. 2004;45(7):2431-2437.

30. Carrington L, McLeod D, Boulton M. IL-10 and antibodies to TGFbeta2 and PDGF inhibit RPE-mediated retinal contraction. Invest Ophthalmol Vis Sci. 2000;41(5):1210-1216.

31. Connor TB Jr, Roberts AB, Sporn MB, et al. Correlation of fibrosis and transforming growth factor-beta type 2 levels in the eye. J Clin Invest. 1989;83(5):1661-1666.

32. Kon CH, Occleston NL, Aylward GW, Khaw PT. Expression of vitreous cytokines in proliferative vitreoretinopathy: a prospective study. Invest Ophthalmol Vis Sci. 1999;40(3):705-712.

33. Nassar K, Luke J, Luke M, et al. The novel use of decorin in prevention of the development of proliferative vitreoretinopathy (PVR). Graefes Arch Clin Exp Ophthalmol. 2011;249(11):1649-1660. 
34. Kita T. Molecular mechanisms of preretinal membrane contraction in proliferative vitreoretinal diseases and ROCK as a therapeutic target. Nihon Ganka Gakkai Zasshi. 2010;114(11):927-934.

35. Machemer R, Aaberg TM, Freeman HM, IrvineAR, Lean JS, Michels RM. An updated classification of retinal detachment with proliferative vitreoretinopathy. Am J Ophthalmol. 1991;112(2):159-165.

36. Girard P, Mimoun G, Karpouzas I, Montefiore G. Clinical risk factors for proliferative vitreoretinopathy after retinal detachment surgery. Retina. 1994;14(5):417-424.

37. Pastor JC, de la Rua ER, Martin F. Proliferative vitreoretinopathy: risk factors and pathobiology. Prog Retin Eye Res. 2002;21(1): 127-144.

38. Nagasaki H, Shinagawa K, Mochizuki M. Risk factors for proliferative vitreoretinopathy. Prog Retin Eye Res. 1998;17(1):77-98.

39. Ricker LJ, Kessels AG, de Jager W, Hendrikse F, Kijlstra A, la Heij EC. Prediction of proliferative vitreoretinopathy after retinal detachment surgery: potential of biomarker profiling. Am J Ophthalmol. Epub April 26, 2012.

40. Yang CS, Khawly JA, Hainsworth DP, et al. An intravitreal sustainedrelease triamcinolone and 5-fluorouracil codrug in the treatment of experimental proliferative vitreoretinopathy. Arch Ophthalmol. 1998;116(1):69-77.

41. Borhani H, Peyman GA, Rahimy MH, Thompson H. Suppression of experimental proliferative vitreoretinopathy by sustained intraocular delivery of 5-FU. Int Ophthalmol. 1995;19(1):43-49.

42. Moritera T, Ogura Y, Yoshimura N, et al. Biodegradable microspheres containing adriamycin in the treatment of proliferative vitreoretinopathy. Invest Ophthalmol Vis Sci. 1992;33(11):3125-3130.

43. Hui YN, Liang HC, Cai YS, Kirchhof B, Heimann K. Corticosteroids and daunomycin in the prevention of experimental proliferative vitreoretinopathy induced by macrophages. Graefes Arch Clin Exp Ophthalmol. 1993;231(2):109-114.

44. Tano Y, Chandler D, Machemer R. Treatment of intraocular proliferation with intravitreal injection of triamcinolone acetonide. Am J Ophthalmol. 1980;90(6):810-816.

45. Rubsamen PE, Cousins SW. Therapeutic effect of periocular corticosteroids in experimental proliferative vitreoretinopathy. Retina. 1997;17(1): 44-50.

46. Koerner F, Merz A, Gloor B, Wagner E. Postoperative retinal fibrosis a controlled clinical study of systemic steroid therapy. Graefes Arch Clin Exp Ophthalmol. 1982;219(6):268-271.

47. Hui YN, Hu D. Prevention of experimental proliferative vitreoretinopathy with daunomycin and triamcinolone based on the time course of the disease. Graefes Arch Clin Exp Ophthalmol. 1999; 237(7):601-605.

48. Jonas JB, Hayler JK, Panda-Jonas S. Intravitreal injection of crystalline cortisone as adjunctive treatment of proliferative vitreoretinopathy. $\mathrm{Br}$ J Ophthalmol. 2000;84(9):1064-1067.

49. Bali E, Feron EJ, Peperkamp E, Veckeneer M, Mulder PG, van Meurs JC. The effect of a preoperative subconjuntival injection of dexamethasone on blood-retinal barrier breakdown following scleral buckling retinal detachment surgery: a prospective randomized placebo-controlled double blind clinical trial. Graefes Arch Clin Exp Ophthalmol. 2010;7:957-962.

50. Chen W, Chen H, Hou P, Fok A, Hu Y, Lam DS. Midterm results of lowdose intravitreal triamcinolone as adjunctive treatment for proliferative vitreoretinopathy. Retina. 2011;31(6):1137-1142.

51. Asaria RH, Kon CH, Bunce C, et al. Adjuvant 5-fluorouracil and heparin prevents proliferative vitreoretinopathy: results from a randomized, double-blind, controlled clinical trial. Ophthalmology. 2001;108(7): 1179-1183.

52. Wickham L, Bunce C, Wong D, McGurn D, Charteris DG. Randomized controlled trial of combined 5-fluorouracil and low-molecularweight heparin in the management of unselected rhegmatogenous retinal detachments undergoing primary vitrectomy. Ophthalmology. 2007;114(4):698-704.
53. Sundaram V, Barsam A, Virgili G. Intravitreal low molecular weight heparin and 5-fluorouracil for the prevention of proliferative vitreoretinopathy following retinal reattachment surgery. Cochrane Database Syst Rev. 2010;7:CD006421.

54. Wiedemann P, Hilgers RD, Bauer P, Heimann K. Adjunctive daunorubicin in the treatment of proliferative vitreoretinopathy: results of a multicenter clinical trial. Daunomycin Study Group. Am J Ophthalmol. 1998;126(4):550-559.

55. Kumar A, Nainiwal S, Choudhary I, Tewari HK, Verma LK. Role of daunorubicin in inhibiting proliferative vitreoretinopathy after retinal detachment surgery. Clin Experiment Ophthalmol. 2002;30(5): 348-351.

56. Lemor M, de Bustros S, Glaser BM. Low-dose colchicine inhibits astrocyte, fibroblast, and retinal pigment epithelial cell migration and proliferation. Arch Ophthalmol. 1986;104(8):1223-1225.

57. van Bockxmeer FM, Martin CE, Thompson DE, Constable IJ. Taxol for the treatment of proliferative vitreoretinopathy. Invest Ophthalmol Vis Sci. 1985;26(8):1140-1147.

58. Daniels SA, Coonley KG, Yoshizumi MO. Taxol treatment of experimental proliferative vitreoretinopathy. Graefes Arch Clin Exp Ophthalmol. 1990;228(6):513-516.

59. Berman DH, Gombos GM. Proliferative vitreoretinopathy: does oral low-dose colchicine have an inhibitory effect? A controlled study in humans. Ophthalmic Surg. 1989;20(4):268-272.

60. Campochiaro PA, Hackett SF, Conway BP. Retinoic acid promotes density-dependent growth arrest in human retinal pigment epithelial cells. Invest Ophthalmol Vis Sci. 1991;32(1):65-72.

61. Fekrat S, de Juan E Jr, Campochiaro PA. The effect of oral 13-cis-retinoic acid on retinal redetachment after surgical repair in eyes with proliferative vitreoretinopathy. Ophthalmology. 1995;102(3): 412-418.

62. Chang YC, Hu DN, Wu WC. Effect of oral 13-cis-retinoic acid treatment on postoperative clinical outcome of eyes with proliferative vitreoretinopathy. Am J Ophthalmol. 2008;146(3):440-446.

63. Pan YT, Elbein AD. The formation of lipid-linked oligosaccharides in Madin-Darby canine kidney cells. Changes in oligosaccharide profiles induced by glucosamine. J Biol Chem. 1982;257(6):2795-2801.

64. Chesnokov V, Sun C, Itakura K. Glucosamine suppresses proliferation of human prostate carcinoma DU145 cells through inhibition of STAT3 signaling. Cancer Cell Int. 2009;9:25.

65. Chang YH, Horng CT, Chen YH, et al. Inhibitory effects of glucosamine on endotoxin-induced uveitis in Lewis rats. Invest Ophthalmol Vis Sci. 2008;49(12):5441-5449.

66. Chen JT, Chen PL, Chang YH, Chien MW, Chen YH, Lu DW. Glucosamine sulfate inhibits leukocyte adhesion in response to cytokine stimulation of retinal pigment epithelial cells in vitro. Exp Eye Res. 2006;83(5):1052-1062.

67. Liang CM, Tai MC, Chang YH, et al. Glucosamine inhibits epidermal growth factor-induced proliferation and cell-cycle progression in retinal pigment epithelial cells. Mol Vis. 2010;16:2559-2571.

68. Liang CM, Tai MC, Chang YH, et al. Glucosamine inhibits epithelial-to-mesenchymal transition and migration of retinal pigment epithelium cells in culture and morphologic changes in a mouse model of proliferative vitreoretinopathy. Acta Ophthalmol. 2011;89(6): e505-e514.

69. Mandava N, Blackburn P, Paul DB, et al. Ribozyme to proliferating cell nuclear antigen to treat proliferative vitreoretinopathy. Invest Ophthalmol Vis Sci. 2002;43(10):3338-3348.

70. Schiff WM, Hwang JC, Ober MD, et al. Safety and efficacy assessment of chimeric ribozyme to proliferating cell nuclear antigen to prevent recurrence of proliferative vitreoretinopathy. Arch Ophthalmol. 2007; 125(9):1161-1167.

71. Kuo HK, Wu PC, Yang PM, Chen YH, Wu YC, Hu DN. Effects of topoisomerase II inhibitors on retinal pigment epithelium and experimental proliferative vitreoretinopathy. J Ocul Pharmacol Ther. 2007; 23(1):14-200. 
72. Turgut B, Uyar F, Ustundag B, Celiker U, Akpolat N, Demir T. The impact of tacrolimus on growth factors in experimental proliferative vitreoretinopathy. Retina. 2012;32(2):232-241.

73. Tahara YR, Sakamoto TR, Oshima YR, et al. The antidepressant hypericin inhibits progression of experimental proliferative vitreoretinopathy. Curr Eye Res. 1999;19(4):323-329.

74. Machado RA, Casella AM, Malaguido MR, Oguido AP. Experimental study of vitreoretinal proliferation inhibition by the use of hypericin. Arq Bras Oftalmol. 2009;72(5):650-654.

75. Imai K, Loewenstein A, Koroma B, Grebe R, de Juan E Jr. Herbimycin A in the treatment of experimental proliferative vitreoretinopathy: toxicity and efficacy study. Graefes Arch Clin Exp Ophthalmol. 2000;238(5): 440-447.

76. Eibl KH, Lewis GP, Betts K, et al. The effect of alkylphosphocholines on intraretinal proliferation initiated by experimental retinal detachment. Invest Ophthalmol Vis Sci. 2007;48(3):1305-1311.
77. Ito S, Sakamoto T, Tahara Y, et al. The effect of tranilast on experimental proliferative vitreoretinopathy. Graefes Arch Clin Exp Ophthalmol. 1999;237(8):691-696.

78. Oshima Y, Sakamoto T, Hisatomi T, Tsutsumi C, Ueno H, Ishibashi T. Gene transfer of soluble TGF-beta type II receptor inhibits experimental proliferative vitreoretinopathy. Gene Ther. 2002;9(18):1214-1220.

79. de Souza OF, Sakamoto T, Kimura H, et al. Inhibition of experimental proliferative vitreoretinopathy in rabbits by suramin. Ophthalmologica. 1995;209(4):212-216

80. Yu HG, Chung H. Antiproliferative effect of mitomycin C on experimental proliferative vitreoretinopathy in rabbits. Korean $J$ Ophthalmol. 1997;11(2):98-105.

81. Lei H, Velez G, Cui J, et al. N-acetylcysteine suppresses retinal detachment in an experimental model of proliferative vitreoretinopathy. Am J Pathol. 2010;177(1):132-140.
Clinical Ophthalmology

\section{Publish your work in this journal}

Clinical Ophthalmology is an international, peer-reviewed journal covering all subspecialties within ophthalmology. Key topics include: Optometry; Visual science; Pharmacology and drug therapy in eye diseases; Basic Sciences; Primary and Secondary eye care; Patient Safety and Quality of Care Improvements. This journal is indexed on

Submit your manuscript here: http://www.dovepress.com/clinical-ophthalmology-journal

\section{Dovepress}

PubMed Central and CAS, and is the official journal of The Society of Clinical Ophthalmology (SCO). The manuscript management system is completely online and includes a very quick and fair peer-review system, which is all easy to use. Visit http://www.dovepress.com/ testimonials.php to read real quotes from published authors. 